\title{
The design of the working equipment for laying a drip tape based on the Grimme GF-75/4 ridge former
}

\author{
N.B. Martynova* and V.I. Balabanov \\ Russian State Agricultural University - MSHA named after K.A. Timiryazev, 127550 Moscow, \\ Russian Federation
}

\begin{abstract}
The article examines statistical data on the amount of precipitation in the spring - summer period and substantiates the need for irrigation measures when growing potatoes in the Moscow region. The rationality of the use of drip irrigation as the most economical and effective method of watering has been proved. With drip irrigation, there is practically no danger of excessive watering, causing the leaching of nutrients from the root layer, an increase in the level of groundwater, and an additional load on the drainage network. The use of drip irrigation will make it possible to maintain an optimal water and air balance during the growing season. The possibility of combining technological operations for laying a drip tape and forming potato ridges is considered. It is found that the resistance of the drip tape laying will not create significant traction resistance, so the working equipment can be mounted on the ridge former. The design of a drip tape stacker based on the Grimme GF-75/4 ridge former was developed and a mechanized drip tape was laid in a potato ridge. It has been proven that the implementation of the drip tape laying and the formation of ridges with one machine will increase the productivity of the work and reduce the energy consumption.
\end{abstract}

\section{Introduction}

The amount of precipitation that falls during the growing season in the Moscow region varies widely, high-water years alternate with low-water ones. The difference in the amount of precipitation in the spring - summer period in different years varies 2 - 4 times [1]. Often precipitation is of a stormy nature, the precipitated moisture can not be absorbed into the soil for the lack of time and goes into the runoff. Precipitation during this period is extremely uneven. Days with heavy rains, when their daily fallout can amount to tens of millimeters, alternate with days and even weeks when there is no precipitation [2,3].

When growing potatoes throughout the growing season, water consumption also changes. In the initial phase of development, the plant has sufficient moisture reserves of the parent root tuber and there is practically no need for additional moisture [4]. However, during this period, the soil is filled with moisture formed in the process of snow melting. In subsequent phases of development, the volume of daily water consumption increases. The maximum

${ }^{*}$ Corresponding author: nmartinova@rgau-msha.ru 
values are observed during the period of flowering and the end of the growth of tops $[5,6]$. Further, the daily water consumption decreases slightly (Fig. 1). As the graph shows, in order to obtain a sustainable harvest of a number of agricultural crops, in particular potatoes, additional irrigation is required.

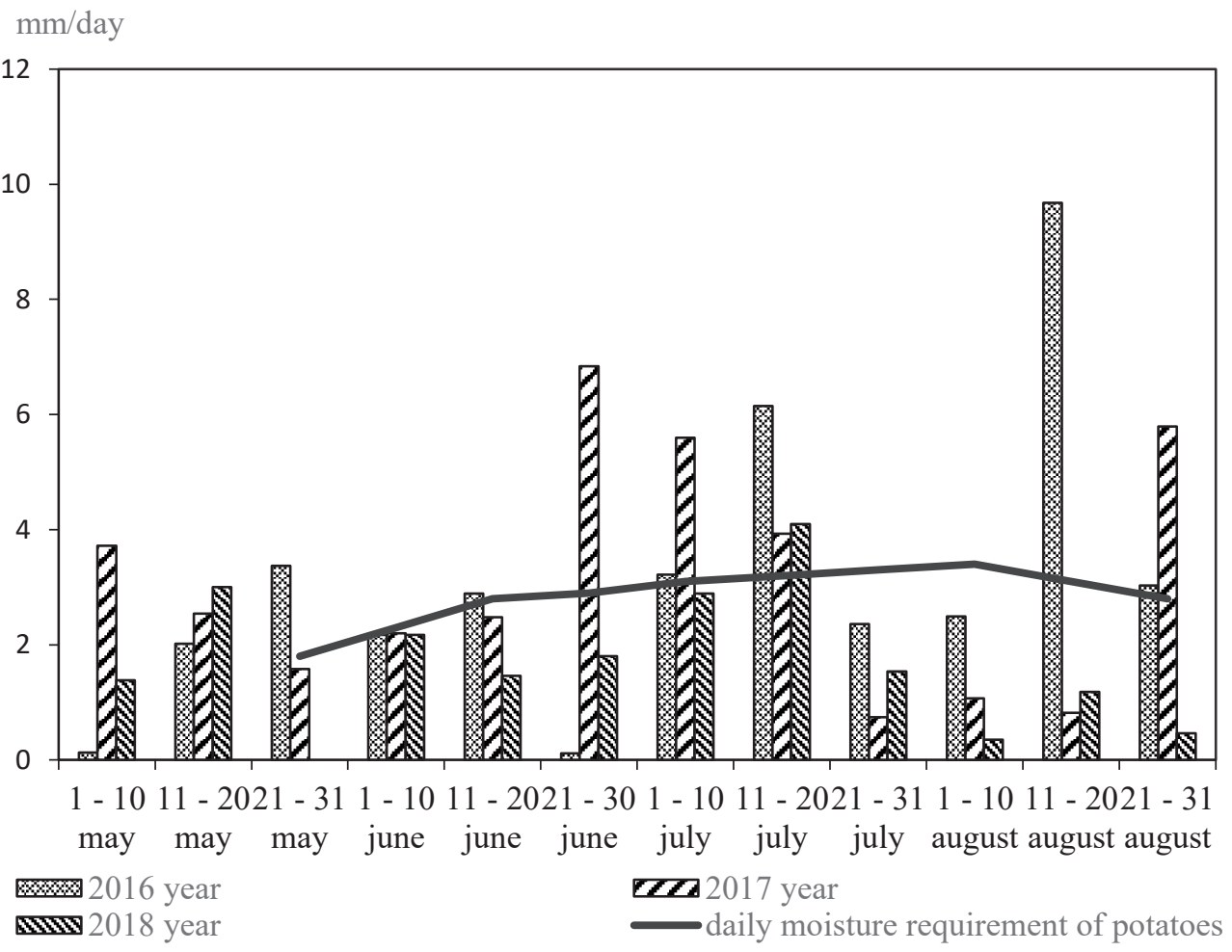

Fig. 1. Dynamics of precipitation in the spring-summer period and the need for moisture in potatoes

Among the irrigation agrarian-meliorative measures, drip irrigation is the most economical. The undoubted advantage of this irrigation method is the delivery of water directly to the root zone $[7,8]$. This, in addition to saving water and electricity, practically eliminates excessive watering, and, consequently, leaching of nutrients from the root zone, raising the level of groundwater, and additional load on the drainage network. In addition, in contrast to surface irrigation, during drying, a dense crust does not form, which makes it difficult to aerate the soil. With drip irrigation, the spacing is practically not moistened, this leads to a slowdown in the growth of weeds $[9,10]$.

The area occupied by drip irrigation in the Russian Federation is about 51 thousand hectares, which is an insignificant percentage of 4633 thousand hectares of the area of all irrigated land. This index is below the world average and is significantly inferior to countries such as the United States or Israel. Pace of drip irrigation implementation is significantly lower than in a number of Asian countries [11].

One of the limiting factors is the low degree of mechanization when laying the drip tape. The equipment designed for mechanized laying of drip tape to the depth of $0.45 \mathrm{~m}$ is serially produced in the USA by Andros, Rain Flo, Kennco Manufacturing [12]. However, these tools are expensive and are not designed to put drip tape into a potato ridge. The use of primitive devices for laying the drip tape causes the uneven tension and breaks or bends of the tape.

\section{Materials and methods}


It is rational to lay the drip tape when growing potatoes in conjunction with the technological operation for the ridges formation, 10 - 14 days after planting. During this period, an increase in daily water consumption of the plant begins, and the combination of operations for ridges formation and laying of a drip tape will increase the work performance, reduce energy consumption $[13,14]$.

To lay the drip tape into the potato ridge, the equipment was developed for installation on the ridge former (Fig. 2), consisting of a frame on which a guide tube with a colter is fixed to place the drip tape in the ridge at the specified depth. The laying depth is adjusted by vertical movement of the pipe using the holder. On the vertical column of the frame there is an axle with clamping discs for fixing the coil. To prevent the tape from unwinding by inertia in the event of a sudden stop of the machine, a brake device with a tension roller and a springloaded pressure shoe is used. During the movement of the machine, the tape is unwound from the coil and enters the guide tube, along which it moves into the potato ridge.

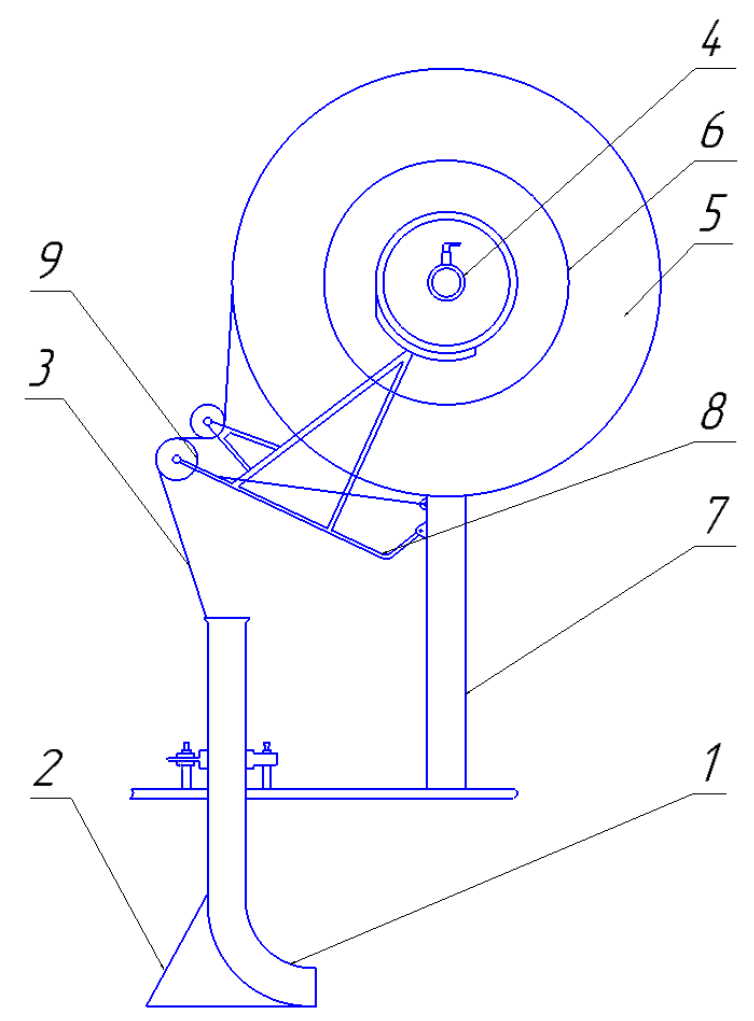

Fig. 2. Construction of drip tape stacker: 1 - guide tube, 2 - opener, 3 - drip tape, 4- shaft, 5 - coil of drip tape, 6 - protective disc with latch, 7 - vertical support post, 8 - braking device, 9 - tensioning roller.

To determine the possibility of installing additional equipment for laying the drip tape on the ridge former, you should calculate the resistance of the drip tape laying, which will be the sum of the soil resistance to development, the friction of the tape in the stacker, overcoming the unbalance of the coil and its friction on the axis $[15,16]$ :

$$
\begin{gathered}
F_{p o}=R_{\text {нг }}+F_{\text {лвр }}+F_{\text {лдр }}+F_{\text {лтр }}= \\
=\mu \cdot G_{p}+k_{p} \cdot h \cdot b+\varepsilon \cdot h \cdot b \cdot v^{2}+
\end{gathered}
$$




$$
+\left(f_{o} \cdot G_{\text {л }} \cdot d_{o} \cdot d_{p}^{-1}+2 \cdot G_{\text {л }} \cdot l_{\ni} \cdot d_{p}^{-1}\right) \cdot\left(1+\mathrm{e}^{f_{o} \cdot \beta}\right),
$$

Where $F_{l v}$ is the tape pulling resistance, $F_{l v r}$ - friction resistance of the tape in the stacker, $\mathrm{kN} ; F_{l d r}$ - force to overcome the unbalance of the coil, $\mathrm{kN} ; F_{l t r}$ - resistance to friction of the coil on the axis, $\mathrm{kN} ; R_{n g}$ - soil resistance to the development, $\mathrm{kN} ; f_{o}$ coefficient of friction of the axle in the bearings; $G_{l}$ - weight of the tape coil, $\mathrm{kN} ; d_{o}$ - axis diameter, $\mathrm{m} ; d_{p}$ is the diameter of the coil, $\mathrm{m} ; l_{e}$ - displacement of the spool center of gravity from the axis of rotation, $\mathrm{m} ; \beta$ - tape wrap angle; $\mu$ coefficient of friction of the working tool on the ground; $G_{p}$ - stacker weight, $\mathrm{kN} ; k_{p}$ - resistivity to cutting, $\mathrm{kN} / \mathrm{m}^{2} ; \varepsilon$ - coefficient that takes into account the effect of cutting speed on the resistance to digging; $h$-development depth, $\mathrm{m} ; b$ - development width, $\mathrm{m}$.

As calculations have shown, when installing additional equipment on the ridge former, the pulling force will increase by $6-8 \%$, which will not affect the performance of the machine, therefore, it is possible to carry out operations to form ridges and lay a drip tape by means of one machine in the same agrarian technical terms (Fig. 3).

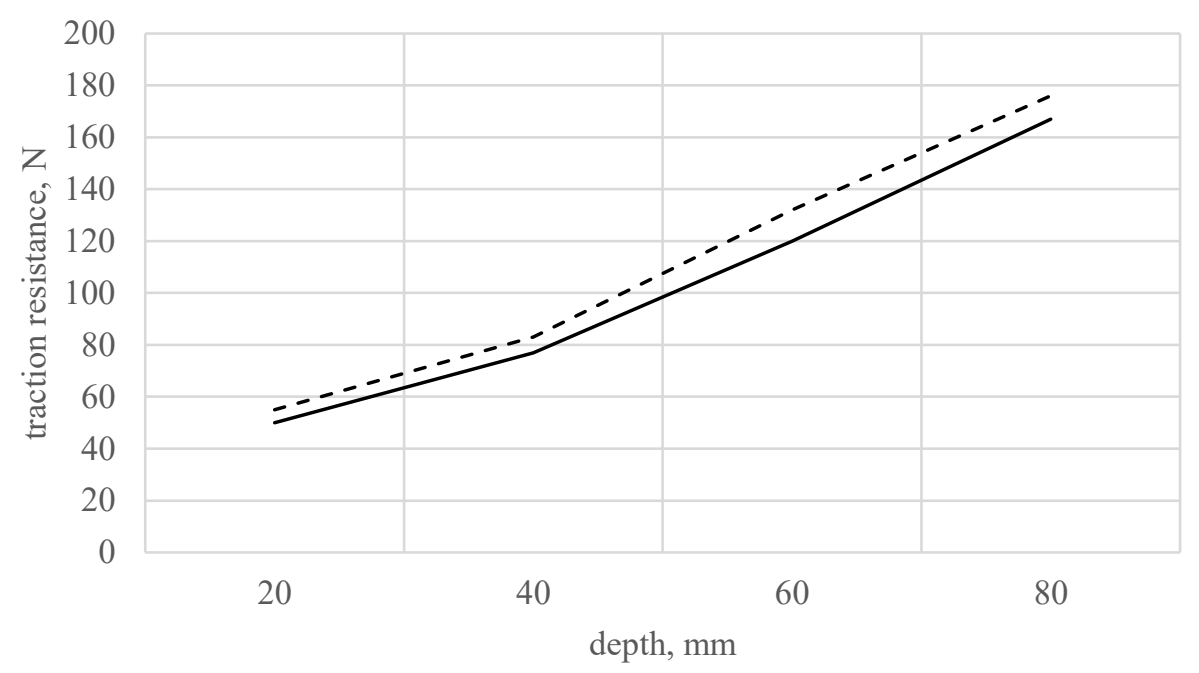

- speed $2 \mathrm{~m} / \mathrm{min} \quad---\operatorname{speed} 2,5 \mathrm{~m} / \mathrm{min}$

Fig. 3. Depth dependence of the drip tape laying resistance.

\section{Results and discussion}

According to the research results, the working equipment was mounted on the Grimme GF75/4 ridge former and the drip tape was laid at the Field Experimental Station of the RGAUMSHA (Russian State Agricultural University) named after K.A. Timiryazev. During the field research, the conditions for performing the technological operation for laying the drip tape were tried out, the optimal speed mode and the time for performing the operation were determined (Fig. 4). 


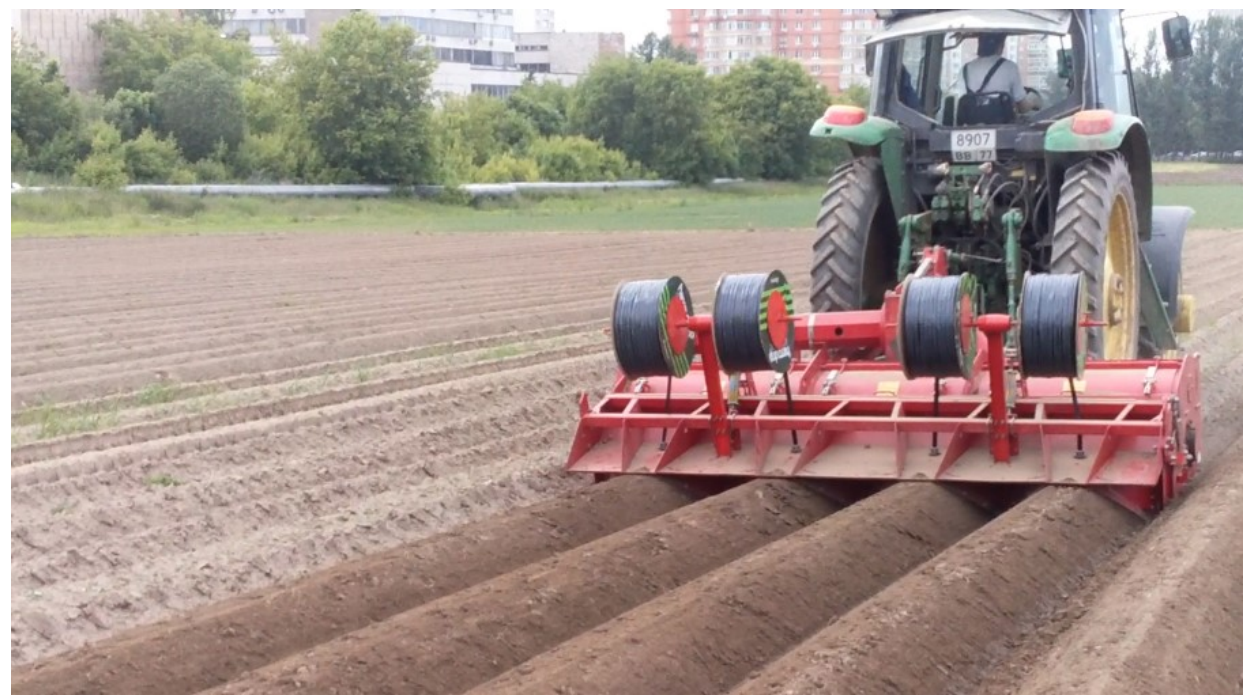

Fig. 4. Ridge-based drip tape stacker Grimme GF-75/4.

Based on the potato planting scheme, a drip tape with a diameter of $16 \mathrm{~mm}$ with a distance between emitters of $300 \mathrm{~mm}$ was chosen. The parameters of the developed machine are presented in Table 1.

Table 1. Technical characteristics of the developed machine.

\begin{tabular}{ll}
\hline Working body weight & $2150 \mathrm{~kg}$ \\
\hline Working body width & $3,0 \mathrm{~m}$ \\
\hline Working speed & $0,9-1,4 \mathrm{~m} / \mathrm{sec}$ \\
\hline Performance & $0,51-0,97 \mathrm{ha} / \mathrm{h}$ \\
\hline Drip tape diameter & $16 \mathrm{~mm}$ \\
\hline Dripper water consumption & $1,6 \mathrm{~L} / \mathrm{h}$ \\
\hline Dripper spacing & $300 \mathrm{~mm}$ \\
\hline
\end{tabular}

Watering was carried out in all subsequent phases of the growing season until the beginning of the wilting of the tops. Watering was carried out at a soil moisture content of $70 \%$ of the PPV at a constant rate, with the adjustment of the time between waterings (Fig. $5)$. 


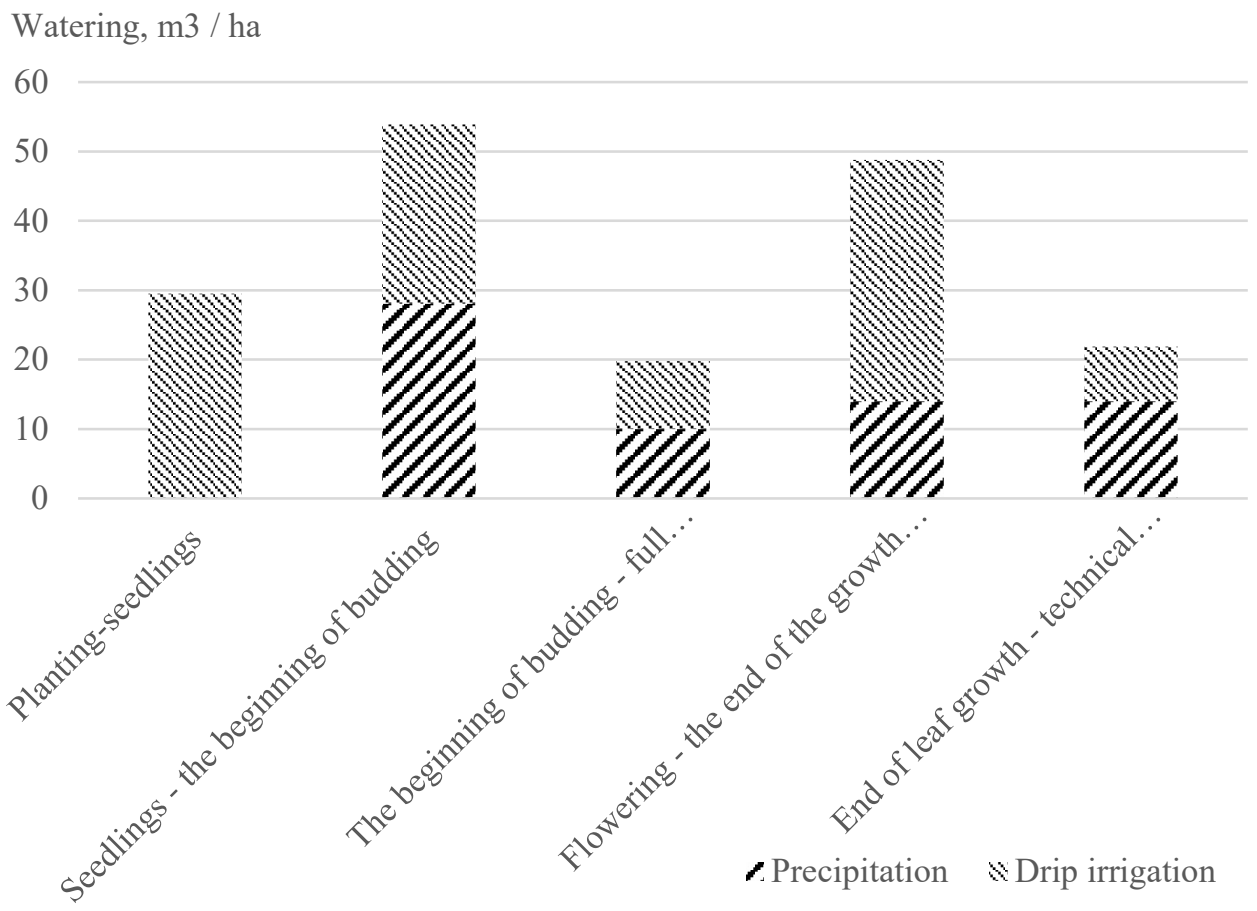

Fig. 5. Water consumption of potatoes at different stages of development.

\section{Conclusion}

When growing potatoes in the Moscow region, irrigation is required to obtain sustainable yields. Drip irrigation will make it possible to moisturize the root zone without over-watering. Drip irrigation will make it possible to maintain optimal water and air balance during the growing season. It is advisable to lay the drip tape together with the operation for the formation of ridges, as in the early phase of potato development there is no need for additional watering due to the moisture reserves of the parent root tuber. The resistance of the drip tape laying did not exceed $180 \mathrm{~N}$, therefore, the installation of the working equipment for the drip tape laying on the ridge former will not cause a significant increase in traction resistance and will not affect the operational characteristics of the machine. The developed design of the drip tape stacker based on the Grimme GF-75/4 ridge former will increase work productivity and reduce energy costs due to the joint implementation of technological operations.

\section{Acknowledgements}

The article was prepared with the support of the Ministry of Education and Science of Russia within the framework of agreement No. 075-15-2021-032 dated March 23, 2021 on the provision of a grant in the form of a subsidy for the creation and development of an engineering center on the basis of an educational institution of higher education and (or) a scientific organization in within the framework of the federal project "Development of infrastructure for research and training" of the national project "Science and Universities". 


\section{References}

1. N.N. Dubenok, Bolotin D.A., Novikov A.A., Bolotin A.G. Bulletin of the Nizhnevolzhsky agro-university complex: science and higher professional education, 51 (3), 81 (2018)

2. O.A. Starovojtova, N.E. Shabanov, The Herald of the Moscow State Agricultural Engineering University named after V.P. Goryachkin, 74 (4), 34 (2016)

3. J. Reyes-Cabrera, L. Zotarelli, M.D. Dukes, D.L. Rowland, S.A. Sargent, Agricultural Water Management, 169, 183 (2016)

4. N.B. Martynova, A.Yu. Korneev, The Herald of the Moscow State Agricultural Engineering University named after V.P. Goryachkin, 84 (2), 18 (2018)

5. A.S. Shtahko, V.N. Shkura, Scientific journal of the Russian Research Institute of Melioration Problems, 31 (3), 39 (2018)

6. S.M. Vasiljev, V.N. Shkura, A.S. Shtahko, Bulletin of the Nizhnevolzhsky agrouniversity complex: science and higher professional education, 52 (4), 316 (2018)

7. Kh.A. Abdulmazhidov, A.S. Matveyev, The Herald of the Moscow State Agricultural Engineering University named after V.P. Goryachkin, 72(2), 40 (2016)

8. A.S. Ovchinnikov, A.A. Buber, Yu.P. Dobrachev, V.V. Borodychev, Bulletin of the Nizhnevolzhsky agro-university complex: science and higher professional education, $\mathbf{5 4}$ (4), 65 (2018)

9. A.S. Ovchinnikov, V.S. Bocharnikov, M.P. Mesherjakov, O.V. Bocharnikova, Bulletin of the Nizhnevolzhsky agro-university complex: science and higher professional education, 48 (4), 10 (2017)

10. N.N. Dubenok, D.A. Bolotin, S.D. Fomin, A.G. Bolotin, Bulletin of the Nizhnevolzhsky agro-university complex: science and higher professional education, 48 (4), 22 (2017)

11. M.N. Makani, S.A. Sargent, L. Zotarelli, D.J. Huber, C.A. Sims, Scientia Horticulturae, 197, 428 (2015)

12. J. Reyes-Cabrera, L. Zotarelli, D.L. Rowland, M.D. Dukes, S.A. Sargent, American Journal of Potato Research, 91 (5), 504 (2015)

13. V.N. Krasnoshchekov, D.G. Olgarenko, Environmental Management, 4, 51 (2016)

14. B.M. Kizjaev, N.B. Martinova, Irrigation and Reclamation, 13(3), 62 (2018)

15. E.V. Zhalnin, The Herald of the Moscow State Agricultural Engineering University named after V.P. Goryachkin, 82 (6), 10 (2017)

16. V.I. Balabanov, A. Li, The Herald of the Moscow State Agricultural Engineering University named after V.P. Goryachkin, 95(1), 10 (2020) 